\title{
GAMIFICAÇÃO E ENSINO DE LÓGICA NA MATEMÁTICA: DISCUSSÕES A PARTIR DE UM LEVANTAMENTO BIBLIOGRÁFICO
}

\author{
Lucas Linke Nunes ${ }^{1}$; Luis Sebastião Basbosa Bemme ${ }^{2}$
}

\section{RESUMO}

Esta é uma pesquisa de caráter qualitativo que tem como objetivo apresentar e discutir o ensino da lógica matemática e o uso da gamificação no ensino a partir de um levantamento bibliográfico. Para isso, foram pesquisadas publicações sobre os assuntos citados na plataforma Scientific Eletronic Library Online (SciELO) e a Plataforma Sucupira, entre os anos de 2010 e 2020. Os dados foram analisados em dois eixos de análise, os resultados indicam que há pouca produção sobre a temática e que a mesma é rica em possibilidades para o ensino.

Palavras-chave: Qualitativo; ScieELO; Plataforma Sucupira.

\section{Eixo Temático: Educação, Cultura e Comunicação (ECC)}

\section{INTRODUÇÃO}

É habitual ouvir de pessoas de todas as idades que a matemática é muito difícil, chata, desinteressante, que só tem números e que é impossível entender, ou ainda que ela não serve para nada na vida, entre tantas outras colocações.

Santos (2008), afirma que esses tipos de significados atribuídos à matemática estão enraizados e até dirigindo as práticas escolares, criando um ciclo vicioso, colocando como um problema central e dificultando o ensino.

Não é novidade que os métodos de ensinos estão, em grande parte, ultrapassados e que isso implica em falta de interesse por parte dos estudantes. Segundo D’Ambrósio (1991) há algo de errado com a matemática que estamos ensinando, muitos dos conteúdos que tentamos ensinar nas escolas são obsoletos, desinteressantes e muitas vezes inúteis.

\footnotetext{
${ }^{1}$ Lucas Linke Nunes - Universidade Franciscana (UFN) lucas_linke@hotmail.com

2 Prof. Dr. Luis Sebastião Barbosa Bemme - Universidade Franciscana (UFN) luisbarbosab@yahoo.com.br
} 
Neste cenário, é preciso investirmos em distintas metodologias que despertem interesse, curiosidade, criatividade e autonomia nos estudantes e nos professores. Também é necessário refletirmos sobre quais conteúdos de fato são essenciais para serem trabalhados nessa disciplina.

Nesse sentido, acreditamos que a lógica matemática deveria ter um papel central nas ações de ensino. Apesar de ter quem pense que o raciocínio lógico sirva apenas para resolver questões e problemas matemáticos ou para certos tipos de jogos e desafios, ele é muito mais que isso, é fundamental para a formação de um cidadão crítico e analítico. Aprender esse tipo de raciocínio, faz com os futuros adultos tenham mais capacidade de analisar se algo está certo ou errado.

De acordo com Leite e Castanheira (2017)

O raciocínio lógico é um modo de pensar, uma forma de resolver problemas a partir da estruturação do pensamento. A lógica matemática se utiliza do raciocínio lógico para a resolução de atividades destinadas ao desenvolvimento de habilidades mentais. Lógica é a ciência do raciocínio. O raciocínio lógico matemático, por sua vez, é o que denominamos raciocínio quantitativo ou lógica quantitativa (LEITE E CASTANHEIRA, 2017, p.13).

Podemos concluir então que, a lógica é a ciência que estudo o raciocínio lógico, o qual, a partir de argumentos, pode nos dizer a veracidade ou falsidade de algo ou alguma situação. Analisamos e procuramos provas e/ou estratégias para defender nossos pensamentos e com isso podemos perceber que ela é a base de todo e qualquer conhecimento científico, não sendo atrelada apenas a Matemática.

Uma das competências específicas prevista para a disciplina de matemática do Ensino Fundamental, presente na Base Nacional Curricular Comum, sublinha a necessidade de "desenvolver o raciocínio lógico, o espírito de investigação e a capacidade de produzir argumentos convincentes, recorrendo aos conhecimentos matemáticos para compreender e atuar no mundo" (BRASIL, 2018, p. 267).

Acreditamos que o desenvolvimento do raciocínio lógico possa ser feito através da gamificação. Essa metodologia tem por objetivo aumentar a motivação, o engajamento, a atenção, a satisfação e outros sentimentos comuns ao se jogar, que podem ser de cunho educacional, coorporativo ou social. (ZICHERMANN; CUNNINGBAM, 2011). 
Uma mesma atividade gamificada tem a liberdade de ser utilizada, com ajustes ou não, em outras áreas além da aplicada originalmente. É importante ressaltar que, apesar de usar elementos de jogos, não tem a necessidade de se usar ou criar um jogo, assim como os exemplos citados anteriormente (ZICHERMANN; CUNNINGBAM, 2011).

Em resumo, podemos dizer que a Gamificação

[...] é um sistema utilizado para a resolução de problemas através elevação e manutenção dos níveis de engajamento por meio de estímulos à motivação intrínseca do indivíduo. Utiliza cenários lúdicos para a simulação e exploração de fenômenos com objetivos extrínsecos apoiados em elementos utilizados e criados em jogos (BUSARELLO, 2016, p.18).

Nesse sentido esta comunicação tem como objetivo apresentar e discutir o ensino da lógica matemática e o uso da gamificação no ensino a partir de um levantamento bibliográfico.

\section{METODOLOGIA}

A pesquisa caracteriza-se como um estudo de caráter qualitativo, pois segundo Prodanov e Freitas (2013), está tem como foco a interpretação dos fenômenos e a atribuição de significados que são básicos no processo de pesquisa, não requerer o uso de técnicas estatísticas e o ambiente natural é a fonte direta para a coleta de dados. Tal pesquisa é descritiva, sendo o processo e seu significado os focos principais de abordagem.

Para o levantamento de tais pesquisas foram utilizadas a plataforma Scientific Eletronic Library Online (SciELO) e a Plataforma Sucupira. Os descritores para busca das produções foram os termos gamificação e ensino de lógica, em um intervalo de tempo entre 2010 e 2020. A análise se deu a partir de dois eixos de análise: Eixo I - Ensino de Lógica e Eixo II - Gamificação no ensino.

A partir dos critérios mencionados foram encontrados 6 trabalhos como mostra o Quadro 01. 
Quadro 01. Número de trabalhos encontrados por descritores.

\begin{tabular}{|l|c|c|c|}
\hline \multicolumn{1}{|c|}{ Descritor } & Scielo & $\begin{array}{c}\text { Plataforma } \\
\text { Sucupira }\end{array}$ & Total \\
\hline Gamificação no ensino & - & 4 & 4 \\
\hline Ensino de Lógica & 1 & 1 & 2 \\
\hline
\end{tabular}

Fonte: Dados da pesquisa

A seguir apresentamos os resultados e discussões oriundos do estudo realizado.

\section{RESULTADOS E DISCUSSÕES}

Os resultados dessa comunicação estão organizados em dois eixos como já mencionado, a seguir discutiremos cada um deles.

\subsection{Ensino de Lógica}

Este eixo é composto por 2 trabalhos que buscam tratar sobre o ensino de lógica, assunto este que, por diversas vezes, acaba sendo pouco abordado, tanto na Educação Básica como no Ensino Superior. O ensino de Lógica é fundamental para o raciocínio tanto de problemas matemáticos quanto de problemas de outros componentes curriculares. Através dele é possível analisar a situação ou questão em particular e chegar a uma ou mais formas de resolver.

No trabalho de Pereira (2016), foram analisados os resultados de uma pesquisa entre licenciandos em Matemática e alunos do Ensino Médio, buscando "destacar a importância da lógica e do raciocínio lógico na formação dos discentes, sobretudo aqueles ligados às ciências exatas". Para isso, buscou validação através de teste $\mathrm{T}$ de Student, $\mathrm{F}$ de Snedecor e teste $Z$ de sete hipóteses levantadas anteriormente.

Concluiu-se, após a análise dos resultados, que é estatisticamente evidenciado que aulas específicas de lógica e raciocínio lógico quantitativo melhoram suas capacidades de resolver problemas lógicos. Assim, através dessa pesquisa, encontraram indícios da relevância do estudo de lógica e raciocínio lógico na escola. $\mathrm{O}$ fracasso dos discentes em matemática e em componentes curriculares ligados às exatas, pode estar relacionado a dificuldade de organizar logicamente os pensamentos. 
No artigo de Silva e Luna (2019), foi pesquisado se problemas de raciocínio lógico e matemático tinham relação com o desempenho escolar de 26 crianças do Ensino Fundamental de uma escola de São Paulo. Essas crianças foram separadas em dois grupos, fortes e fracas, conforme o desempenho em matemática.

Usando o Teste de Correlação de Pearson-r nos resultados de um teste classificatório de Matemática. Os autores chegam à conclusão de que os resultados da pesquisa vão além de lógica e Matemática terem uma correlação. Observaram que a forma como o objeto de conhecimento é ensinada pode estar mais ligado às dificuldades dos alunos do que o próprio conteúdo.

A partir destes trabalhos, foi possível perceber como o raciocínio lógico é importante e pode ser mais incentivado. Pois, melhora a forma de resolver problemas lógicos, ou seja, facilita uma grande parte das situações do cotidiano as quais necessitam um pensamento mais crítico. Isso não significa ser "robotizado" e tratar tudo logicamente, mas conseguir pensar em respostas e estratégias para resolver ou evitar adversidades em suas vidas.

\subsection{Gamificação no ensino}

Este eixo é composto por 4 trabalhos que utilizaram o conceito de gamificação em suas pesquisas. Aqui veremos como o ensino está se utilizando essa ferramenta que, apesar de considerada nova e não possui muitas pesquisas no Brasil, está se mostrando versátil e eficaz. Além disso, por ser ainda pouco explorada e muitos trabalhos ainda não estarem disponíveis nos portais, foram estudados trabalhos de outras áreas além da matemática.

O primeiro trabalho é uma dissertação de mestrado com autoria de Esquiavel (2017). Teve como objetivo "abordar um conceito envolvendo tecnologias de última geração, games e que pode ser aplicado ao ensino". Para isso, analisou o Estado da Arte e a pesquisa de campo com uma turma de $8^{\circ}$ ano do Ensino Fundamental. Foram utilizados os aplicativos para celular "Slice It" e "Euclidea", ambos sobre Geometria.

As considerações desse estudo apontam que a gamificação é uma ferramenta metodológica que mostra sua eficiência na educação por se aproveitar do nosso interesse natural de jogar e de utilizar novas tecnologias, se intensificando 
na educação básica pela faixa etária dos alunos. Além disso, é colocado como é grande sua versatilidade podendo ser aplicada em qualquer conteúdo e/ou componentes curriculares.

Já o trabalho de Moraes (2017), teve como objetivo "o engajamento dos estudantes no estudo das matrizes, através da gamificação no ensino de Matemática". Ele analisou como três livros didáticos apresentavam e desenvolviam o conteúdo de matrizes e expõe três propostas de atividades gamificadas para o ensino.

Em suas considerações finais, o autor ressalta como é interessante que as abordagens com os jovens sejam feitas pensando na interatividade, apresentando um propósito maior que precise ser resolvido com urgência. Mostrando como a gamificação se encaixa muito bem a esses objetivos. Por fim, lembra como é necessário o docente diversificar sua forma de ensino, seja com gamificação ou qualquer outra forma metodológica, mas sempre tendo em vista o desenvolvimento dos alunos.

O terceiro trabalho foi realizado na área da História. Soares (2019), teve como objetivo "desenvolver uma sequência didática baseada em jogos e gamificação, visando à motivação e ao engajamento dos alunos no aprendizado de conteúdos de História (p.14)". A pesquisa foi realizada em uma turma de sétimo ano do Ensino Fundamental e foram analisados, qualitativamente, dados por meio da observação, entrevistas, desempenho na dinâmica, prova e questionários.

Em suas conclusões, o autor observou que após a realização das atividades, a turma pesquisada estava mais estimulada a realizar as tarefas cotidianas, 0 número de faltas diminuiu e a participação dos alunos aumentou significativamente. Ressaltou ainda como as metodologias ativas são importantes na sociedade atual que está em constante competição entre seus integrantes e que a competição é um dos elementos de jogos, mesmo que não tenha sido o foco da pesquisa (SOARES, 2019),

Por último, o trabalho de Silva (2018) foi aplicado na Física, como objetivo "investigar as contribuições da gamificação para motivar a atitude potencialmente significativa dos alunos no ensino de óptica geométrica (p.8)". No início, ele 
menciona como o ensino de Física, em geral, é muito matematizada e sente a necessidade de enaltecer os aspectos físicos em sua pesquisa, assim como trazer mais do cotidiano dos alunos para o conteúdo.

Os sujeitos pesquisados foram de duas turmas de $2^{\circ}$ ano do Ensino Médio dos cursos de Técnico Integrado do Instituto Federal de Educação, Ciência e Tecnologia do Ceará (IFCE), que, através de um questionário, demonstraram mais interesse no conteúdo estudado, mais confiantes ao perceberem seus progressos e satisfeitos ao terminarem as missões. Por fim, o autor percebe a limitação do grupo ser menor que geralmente são as turmas nas escolas. Assim, incentivando novas pesquisas com mais alunos e em diferentes áreas da Física (SILVA, 2018).

A partir desses trabalhos foi possível concluir que a Gamificação pode ser utilizada das mais diversas formas e em diferentes cenários. Tendo o objetivo central o de motivar os participantes, há uma liberdade a mais na criação de atividades pois não é preciso estar preso a um determinado assunto ou problema.

Além disso essa metodologia tem se mostrado uma ferramenta importante para o desenvolvimento de trabalhos interdisciplinas ou integrados entre as distintas áreas do conhecimento.

\section{CONCLUSÃO}

Nessa comunicação tivemos como objetivo apresentar e discutir o ensino da lógica matemática e o uso da gamificação no ensino a partir de um levantamento bibliográfico.

A partir deste levantamento bibliográfico foi possível perceber que ainda se encontram poucos trabalhos com os assuntos de ensino de lógica ou gamificação no ensino e nenhum encontrado com ambos. Talvez por existir um entendimento de que a lógica já está subentendida nos diversos objetos de conhecimento assim não sendo necessário seu estudo específico.

Quanto a gamificação, é um conceito que é oficialmente usado a pouco mais de dez anos e que está começando a ganhar mais visibilidade, logo, terão poucas pesquisas ainda. 
Podemos perceber que a importância do raciocínio lógico e como seu estudo específico ajuda na resolução de problemas nas mais diversas áreas. Assim, tornam as adversidades da vida cotidiana mais fáceis de serem resolvidas, pois serão vistas de perspectivas diferentes das usuais, possibilitando novas estratégias.

Quanto a gamificação, é uma metodologia de ensino que, diferente de outras, não visa estritamente o aprendizado de certo objeto do conhecimento, mas em motivar os discentes a ver o estudo de uma forma diferente. Fazendo com que eles mesmos busquem mais informação por vontade própria. Além disso, é uma metodologia que se encaixa bem com a interdisciplinaridade por ter a liberdade de transitar nos mais diversos assuntos.

Por fim destacamos que tais assuntos necessitam ser aprofundados na pesquisa uma vez que se mostram ferramentas importantes para o desenvolvimento de habilidade aplicadas a distintas áreas do conhecimento.

\section{REFERÊNCIAS}

BRASIL. Ministério da Educação. Base Nacional Comum Curricular. Brasília, 2018.

BUSARELLO, Raul Inácio. Gamification: princípios e estratégias. Editora Pimenta Cultural. São Paulo, SP. 2016.

D’AMBRÓSIO, Ubitatan. Matemática, ensino e educação: uma proposta global. Temas \& Debates, São Paulo, 1991.

ESQUIAVEL, Hugo Caros da Rosa. Gamificação no ensino de matemática: uma experiência no ensino fundamental. Dissertação de mestrado, Universidade Federal Rural do Rio de Janeiro, RJ. 2017.

LEITE, Álvaro Emílio. CASTANHEIRA, Nelson Pereira. Raciocínio lógico e lógica quantitativa. Editora InterSaberes. Curitiba, PR. 2017. 
MORAES, Pedro Gurgel. Gamificação no ensino de matemática: propostas para o ensino de matrizes através de um jogo de realidade alternativa. Dissertação de Mestrado. Universidade Rural do Semi-Árido, Mossoró, RN, 2017.

PEREIRA, Israel Roque. O sucesso escolar na interseção com o ensino da lógica e do raciocínio lógico quantitativo. Dissertação de Mestrado. Universidade Federal de Viçosa, Viçosa, MG, 2016.

PRODANOV, C. C.; FREITAS, E. C. Metodologia do trabalho científico: métodos e técnicas da pesquisa e do trabalho acadêmico. 2 ed. Nova Hamburgo: Feevale, 2013.

SANTOS, Vinício de Macedo. A Matemática escolar, o aluno e o professor: paradoxos aparentes e polarizações em discursos. Cadernos Cedes, Campinas, SP, V. 28, № 74, p. 25-38, jan/abr. 2008.

SILVA, João Batista da. Gamificação de uma sequência didática como estratégia para motivar a atitude potencialmente significativa dos alunos no ensino de Óptica Geométrica. Instituto Federal de Educação, Ciência e Tecnologia do Ceará, CE, 2018.

SILVA, Simone de Oliveira Andrade; LUNA, Sérgio Vasconcelos de. Correlação entre o Raciocínio Lógico e o Raciocínio Matemático em Crianças Escolarizadas. Bolema: Boletim de Educação Matemática [online]. 2019, v. 33, n. 65 [Acessado 17 Setembro 2021] , pp. 1047-1066. Disponível em: <https://doi.org/10.1590/19804415v33n65a04>. Epub 2 Dez 2019. ISSN 1980-4415. https://doi.org/10.1590/1980$4415 v 33 n 65 a 04$.

SOARES, Renan da Cruz Padilha. Jogar para motivar e viver a história: sequência didática baseada em jogos e gamificação. Dissertação de Mestrado, Colégio Pedro II. Rio de Janeiro, RJ, 2019. 
EDUCAÇÃO, SAÚDE

ETECNOLOGIA

26 A 28 DE OUTUBRO DE 2021

\section{QUFN}

ZICHERMANN, G. e CUNNINGHAM, C. Gamification by Design. Sebastopol: O Relly, 2011. 